\title{
41. MAGNETIC ANISOTROPY AND SEDIMENT TRANSPORT DIRECTIONS IN NORTH ATLANTIC EARLY CRETACEOUS BLACK SHALES AND EOCENE MUDSTONES CORED ON DSDP LEG 48
}

\author{
Ernest A. Hailwood and William O. Sayre, Oceanography Department, University of Southampton, S09 5NH, U.K.
}

\section{INTRODUCTION}

The property of anisotropy of magnetic susceptibility (ams) provides a rapid and potentially precise method for estimating the degree and direction of preferred alignment of assemblages of magnetic mineral grains. In the case of sedimentary particles of grain size $>50 \mu \mathrm{m}$ this alignment is commonly due to a combination of gravitational forces, which tend to make elongate grains lie with their long axes in the horizontal plane, and hydrodynamic forces, which cause the long axes to be aligned in a direction related to the azimuth of flow. Under favorable circumstances, determination of this direction of alignment from measurements of the AMS can provide a precise measure of the direction of sediment transport, and place constraints on the possible magnitude of bottom currents. Such information is of considerable value to paleoenvironmental studies.

As part of a wider program aimed at establishing generalized paleocirculation trends during the early stages of opening of the Atlantic Ocean, this paper describes an AMS study carried out on the sequence of Aptian-Albian carbonaceous mudstones ("black shales") recovered from Holes 400A and 402A (northeast Bay of Biscay), and the Paleocene-Eocene glauconitic tuffaceous mudstones from Site 403 (southwest Rockall Plateau), on IPOD Leg 48.

\section{Theoretical Background to AMS}

AMS refers to the variation of magnetic susceptibility with direction, within an individual magnetic mineral grain or within an assemblage of such grains. The magnetic susceptibility, $\chi_{i j}$, represents the relationship between a component of induced intensity of magnetization $\mathrm{Ji}$ and the inducing magnetic field $H_{j}$ :

$$
J_{i}=\chi_{i j} H_{j}
$$

The susceptibility may be conveniently approximated by a triaxial ellipsoid, with three orthogonal principal axes of length $\chi_{\max }, \chi_{\text {int }}$, and $\chi_{\min }$. AMS in rocks commonly originates from two sources, magnetocrystalline anisotropy, in which the principal susceptibility axes are related to the crystallographic axes of the mineral grain, and shape anisotropy which, in elongate mineral grains, may be considered due to variation of the self-demagnetizing factor with direction, such that it is easier to magnetize an elongate grain along its long axis than at right angles to it. One of the commonest sources of AMS in rocks is the mineral titanomagnetite, which is crystallographically isotropic and its observed magnetic anisotropy, therefore, due to shape effects alone. In this case the maximum susceptibility axis will correspond with the long axis of the mineral grain, and in a sediment sample comprising an assemblage of such grains it will define the direction of preferred orientation of grain long axes. As with an individual grain, the AMS of an assemblage of elongate grains may be described by a triaxial ellipsoid.

Extensive laboratory redeposition experiments, summarized by Hamilton and Rees (1970) have demonstrated that in the case of a "primary style" magnetic fabric, formed by grain-by-grain deposition, the $\chi_{\min }$ axis commonly lies close to the vertical. This represents the tendency for elongate grains to lie in the horizontal plane, and consequently to define a "magnetic foliation plane" which is approximately parallel to the bedding. Where deposition occurs from flowing water, the $\chi_{\max }$ axis defines a "magnetic lineation," which normally lies parallel with the direction of flow.

\section{Susceptibility Parameters}

A useful parameter which may be calculated from the magnitude of the principal susceptibility axes is the “"azimuthal anisotropy quotient," $q$ (Rees, 1966):

$$
\mathrm{q}=\frac{2\left(\chi_{\max }-\chi_{\text {int }}\right)}{\chi_{\max }+\chi_{\text {int }}-2 \chi_{\min }}
$$

This parameter represents a measure of the relative magnitude of linear and foliar elements, and ranges in value from zero for a pure foliation to 2.0 for a pure lineation. Studies of natural sediments, together with laboratory redeposition experiments under carefully controlled conditions, indicate that primary (depositional) style fabrics produced by grain-by-grain deposition commonly correspond with values of $q$ in the range 0.06 to 0.67 . Values outside this range frequently represent the effects of secondary processes, such as soft-sediment deformation due to slumping or coring disturbances, or the effect of bioturbation (Hamilton and Rees, 1970). In the present study $q$ values lying within the above range, together with $\chi_{\min }$ directions lying within 15 degrees of the vertical, are considered as indicative of a "primary style" magnetic fabric, which is potentially capable of providing information on bottom transport directions.

\section{Instrumentation}

In this study, all measurements of AMS have been performed on a low field torque magnetometer (LFTM) at an applied field of 100 Oe (peak). The value of the parameter $\Sigma G i \%$ (King and Rees, 1962) was calculated for all samples, from the deflections observed on the LFTM. The parameter provides a measure of instrumental errors, 
and the magnitude of harmonics other than the desired second harmonic in the magnetic torque curves. In the present study, anisotropy determinations from samples whose $\Sigma G_{i} \%$ value exceeded 40 per cent were rejected, on the grounds that they might reflect significant instrumental effects.

\section{Magnetic Constituents}

Thermomagnetic analyses have been carried out on a number of representative samples from Holes 400A, 402A and Site 403, utilizing a horizontal beam thermobalance; a typical thermomagnetic curve is shown in Figure 1. This curve exhibits a well-defined Curie point at $570^{\circ} \mathrm{C}$, and indicates that the dominant magnetic material in these sediments is titanomagnetite, with a composition close to that of pure magnetite. Consequently the observed magnetic anisotropy may be interpreted as due to the shape anisotropy of crystallographically isotropic magnetite, and is likely to reflect the preferred alignment of elongate magnetite grains.

\section{Orientation of Samples}

The paleomagnetic properties of the samples selected for AMS determinations previously had been studied in detail (Hailwood, this volume), and only samples showing a well-defined stable remanence direction were chosen. By assuming that the direction of stable remanence in each sample defines the direction of the geographic azimuth at the time of deposition, it is possible to specify the directions of the three principal susceptibility axes with respect to the contemporaneous north pole. This allows the inferred directions of alignment of magnetic mineral grains to be plotted on paleogeographic reconstructions, and the relevance of the inferred sediment transport directions to be discussed in the context of the paleoenvironmental evolution of the continental margins.

The applicability of this technique for providing azimuthal orientation of inferred sediment transport directions depends upon the assumption that the stable magnetic remanence is carried by the very fine grained ferromagnetic particles, possibly those approaching single domain size $(\sim 0.5 \mu \mathrm{m})$, whereas the AMS is dominated by the effect of larger grains, possibly those exceeding $50 \mu \mathrm{m}$

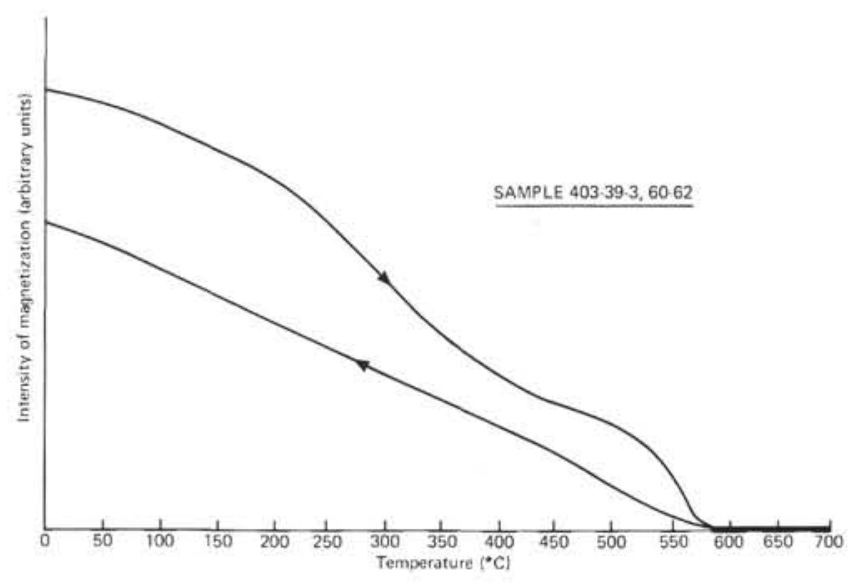

Figure 1. Thermomagnetic curve for typical sample from Site 403 . in size. This assumption is supported by calculations of the approximate values of magnetic, hydrodynamic, and gravitational couples likely to act on particles of differing grain size (e.g., Rees and Woodall, 1975). For particles of $\sim+\mu \mathrm{m}$ in diameter the couple due to the earth's magnetic field acting on the particle's remanence is dominant, but for increasing grain size the magnitude of the hydrodynamic couple increases at a faster rate than that of the magnetic couple. Because of uncertainties in the magnitude of parameters such as fluid drag force, average grain shape, and intensity of magnetization, it is difficult to calculate the theoretical limiting grain size at which hydrodynamic forces will dominate over magnetic aligning forces, but a value of about $50 \mu \mathrm{m}$ is likely for the type of sediments utilized in this study.

The accuracy of the azimuthal orientation provided by the direction of stable remanence will also be governed by the precision with which the remanence is defined, and the extent to which secular variation of the geomagnetic field has been averaged out in a single sample. The stable remanence directions are considered to be defined with a precision of better than \pm 5 degrees for the majority of samples studied from Site 403 , and \pm 15 degrees for those from Holes $400 \mathrm{~A}$ and $402 \mathrm{~A}$. The extent to which secular variation has been averaged out in each sample depends upon the sedimentation rate, assuming the remanence to be detrital in origin. The time necessary for complete averaging of secular variation, so that the mean magnetic pole calculated on the basis of a centered axial dipole model should coincide with the geographic pole, is commonly accepted to be at least $10^{4}$ years. Using the paleontologically determined sedimentation rates at Holes $400 \mathrm{~A}, 402 \mathrm{~A}$ and Site 403 , the time interval represented by a single 2.5 -cm-diameter paleomagnetic sample for each of these sites is $0.2 \times 10^{4}, 0.06 \times 10^{4}$, and $0.03 \times 10^{4}$, respectively. Consequently, relatively complete averaging of geomagnetic secular variation may be anticipated for the samples from Hole 400A, and less-complete averaging for those from Hole 402A and Site 403. Since, at this latitude, the amplitude of declination changes due to geomagnetic secular variation is in the order of 20 to 30 degrees, errors of up to this magnitude may exist in the orientation of susceptibility axes for samples from the latter two sites. However, the magnitude and direction of these errors should differ randomly from one sample to another, so that the mean susceptibility axis orientation derived from a number of samples at a particular site will be subject to a much lower uncertainty than the values quoted above.

\section{RESULTS}

\section{Aptian-Albian Black Shales From Northeast Biscay}

The Aptian-Albian black shales from Holes $400 \mathrm{~A}$ and 402A comprise a sequence of dark colored, organic-rich, carbonaceous mudstones, rhythmically interbedded with layers of lighter colored calcareous mudstone and silty claystone that are relatively depleted in organic material.

The thickness of one complete dark-light rhythm varies from about $30 \mathrm{~cm}$ for the Albian sediments at Hole 400A to $50 \mathrm{~cm}$ for the Aptian sediments at this site, and $100 \mathrm{~cm}$ for those at Hole 402A. 
Samples for magnetic anisotropy determinations were taken only from the dark, organic-rich carbonaceous layers. The reasons for this were twofold. First, the intensity of magnetization of the interbedded light colored layers was generally too weak to allow an accurate determination of stable remanent magnetization for orientation purposes. Second, the dark carbonaceous mudstones appear to have been deposited under relatively anoxic conditions, hostile to the development of benthic communities and therefore not bioturbated; consequently the original primary sedimentary structures are commonly preserved. This low level of post-depositional deformation renders the sediments a particularly attractive target for magnetic fabric studies.

\section{Hole 400A}

A total of 31 samples was selected from the Aptian-Albian carbonaceous mudstones at this site, and the majority of these exhibited "primary-style" fabrics. A contoured equal-area upper hemisphere projection of the maximum and minimum susceptibility axes of these samples is presented in Figure 2. A tight distribution of minimum susceptibility axes exists close to the vertical, indicating the presence of a well-developed near-horizontal magnetic foliation in these sediments. From the clustering of the maximum susceptibility axes in the northeast quadrant, a well-defined magnetic lineation is also identifiable. This lineation may be interpreted in terms of a northeast-southwest preferred alignment of mineral grains resulting from bottom transport in this direction. The subsidiary grouping of maximum susceptibility axes with a northerly trend may indicate that the direction of bottom
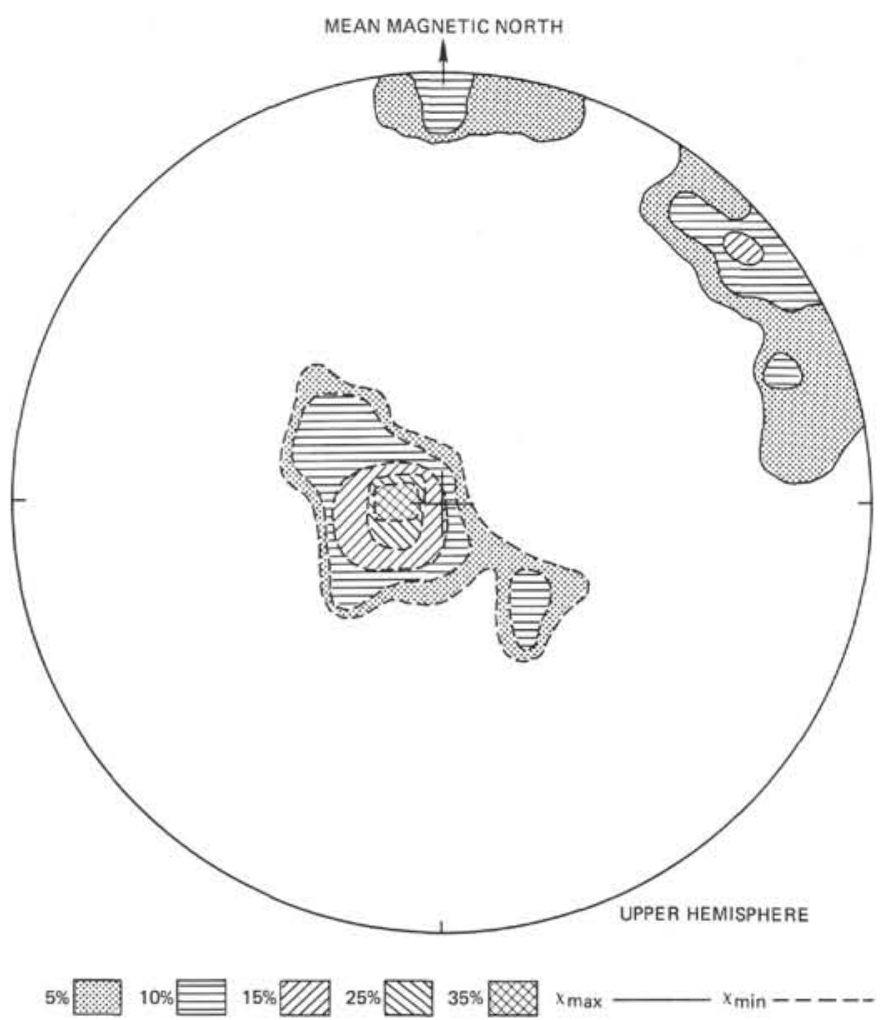

Figure 2. Contoured equal area projection of directions of maximum and minimum principal susceptibility axes for Early Cretaceous samples from Hole $400 \mathrm{~A}$. transport oscillated between a northerly and a northeasterly direction. Alternatively it could represent the dominance of the induced magnetic aligning couple over the hydrodynamic couple during deposition of those samples showing a northerly $\chi_{\max }$ azimuth. Further experiments on the possible relationship between grain size of the magnetic constituents and $\chi_{\max }$ orientation are in progress in this laboratory to attempt to discriminate between these two alternative explanations for the northerly $\chi_{\max }$ azimuths.

The downhole variation of key anisotropy parameters in the Lower Cretaceous carbonaceous mudstones at Hole $400 \mathrm{~A}$ is shown in Figure 3. Because the maximum susceptibility direction is defined by a double-ended axis, there is ambiguity in choosing which end of this axis to plot. In view of the dominant northeast trend of the upward directed ends of these axes revealed by Figure 2, the convention has been adopted of plotting the end closest to the northeast quadrant in Figure 3 . In addition to the dominant north-northeast trend, Figure 3 reveals a systematic, or possibly progressive, shift in azimuth of $\chi_{\max }$ through some 90 to 100 degrees close to the base of the lower Albian.

Laboratory experiments on sediments deposited from a dilute suspension (summarized by Hamilton and Rees, 1970) have demonstrated that a well-developed magnetic lineation accompanied by low $q$ values, typically less than 0.42 , may be produced either by strong and persistent bottom currents (e.g., Hamilton, 1967) or as a result of the shear produced by deposition on a slope (Rees, 1968). There is some suggestion that it might be possible to discriminate between these two mechanisms from the direction of imbrication of the maximum susceptibility axes. In the case of grain-by-grain deposition from bottom currents, the maximum susceptibility axes are commonly tilted through a small angle $\left(\sim 10^{\circ}\right)$ away from the horizontal, with the upward directed ends pointing in a downstream direction. This appears to correspond with the most stable configuration of grain long axes, and is referred to as a negative imbrication. In contrast, initial experiments suggest that deposition on a sloping interface in still water results in the maximum susceptibility axes being tilted upwards in a direction upstream, i.e., the production of a positive imbrication.

The direction of the magnetic lineation at Hole $400 \mathrm{~A}$ is plotted on an Early Cretaceous paleogeographic reconstruction of northwest Europe in Figure 4a. In this reconstruction the orientation of the continental margin has been determined from continental paleomagnetic data (Smith et al., 1973). It is clear from this diagram that the direction of the magnetic lineation at Hole $400 \mathrm{~A}$ is approximately perpendicular to the contemporaneous continental margin. Because it is unlikely that the sediment was transported in an upslope direction, it is reasonable to assume that the observed magnetic lineation was produced by sediment movement toward the southwest, rather than northeast. Consequently, the northeast grouping of the upward directed ends of the AMS (Figure 2) indicates the existence of a positive imbrication. This conclusion suggests that the strongly developed magnetic lineation at this site may have been produced as a result of deposition on a slope. 


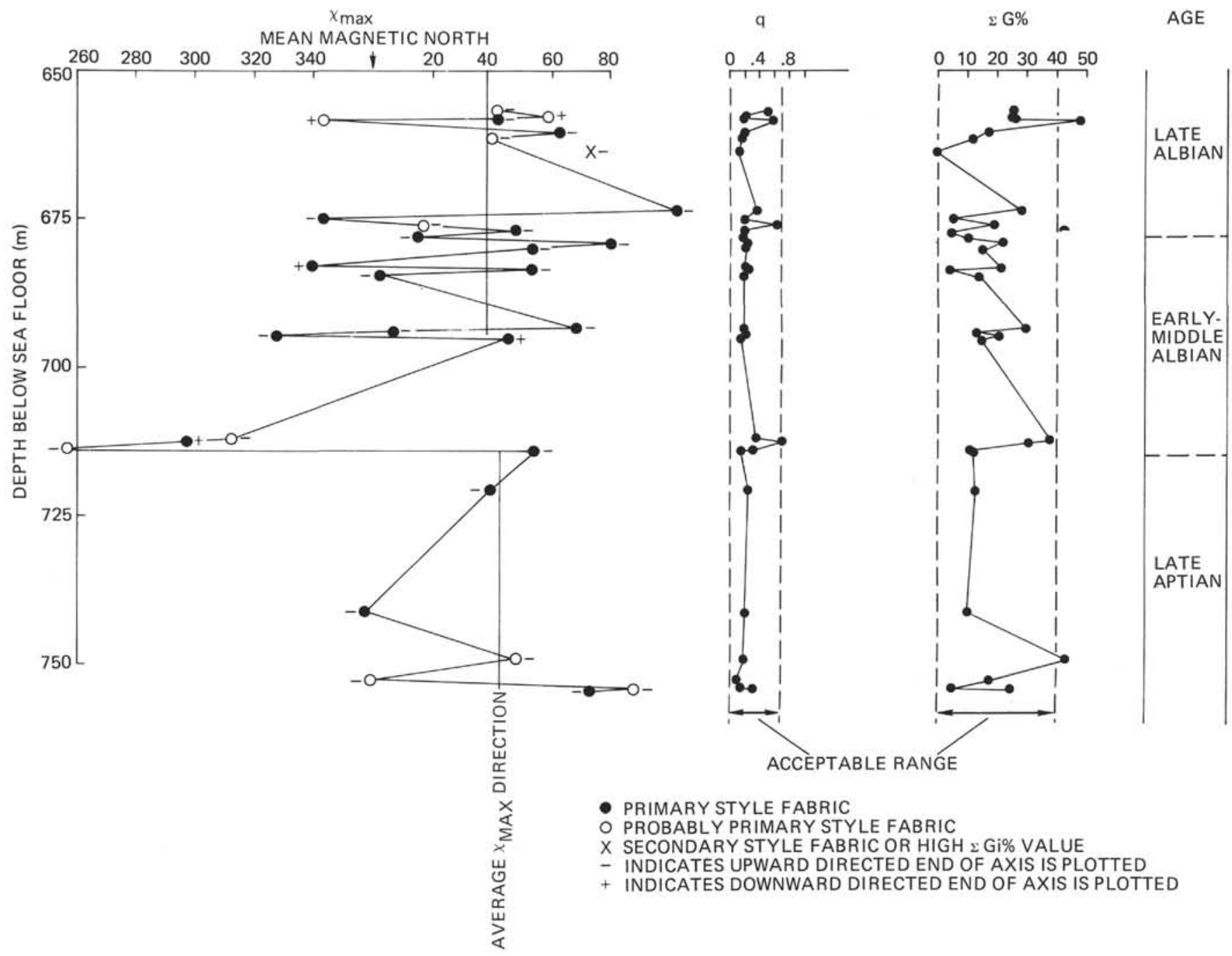

Figure 3. Downhole variation of key susceptibility parameters at Hole 400A. For explanation of symbols see text. "Probably primary style" fabric refers to samples whose susceptibility parameters lie close to, or just outside the accepted range for true primary style fabrics, yet do not show clearly developed secondary style characteristics.

The laboratory experiments discussed above refer to deposition from dilute suspension, in which intergranular interactions are unimportant. Experiments in which sediments were deposited from concentrated dispersions, such as turbidity currents, appear to reveal more complex magnetic fabrics. For example, Rees and Woodall (1975) describe two redeposition experiments in which sand and silt, respectively, were deposited from a density current onto an interface dipping at 6 degrees downstream. A strong positive imbrication was produced for the sand, and a weaker negative imbrication for the silt. Full assessment of the relevance of these, and other experiments for interpreting the Leg 48 anisotropy data, must await detailed grain-size determinations on both the magnetic and non-magnetic fractions, and the outcome of further laboratory redeposition experiments. However they serve to indicate that the positive imbrication of the $X_{\max }$ axes in the Hole $400 \mathrm{~A}$ black shales could have been produced not only by deposition onto a slope from relatively still water, but possibly also by deposition from density currents flowing down the continental slope toward the southwest.

Although magnetic anisotropy determinations were not carried out on the interbedded light-colored calcareous mudstones and silty claystones, these sediments (above a depth of $700 \mathrm{~m}$ ) show abundant evidence of slumping, including flow structures, microfaulting, and slump folding, and may well have been emplaced by mass downslope movement. This supports the suggestion of deposition of the interlaminated dark carbonaceous mudstones on, or near to, a slope.

\section{Hole 402A}

The directions of the maximum and minimum principal susceptibility axes of the 61 samples of Lower Cretaceous mudstone studied from Hole $402 \mathrm{~A}$ are shown on a contoured equal area projection in Figure 5a. As with Hole $400 \mathrm{~A}$, a well-developed near-horizontal magnetic foliation is indicated by the steeply inclined minimum susceptibility 
(a) EARLY CRETACEOUS

(APTIAN-ALBIAN)

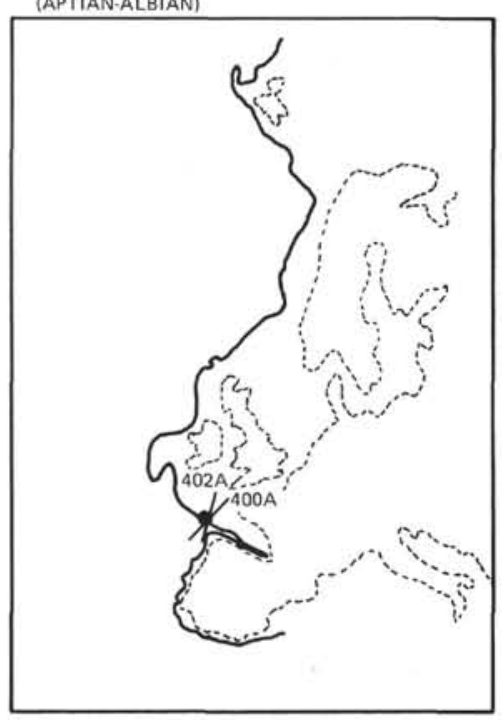

(b) EARLY CENOZOIC

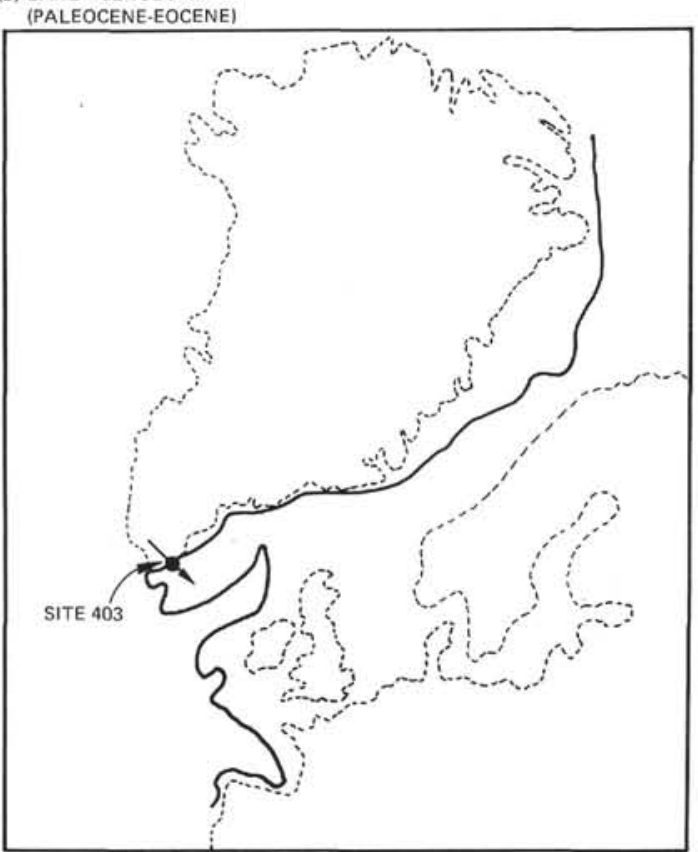

Figure 4. Early Cretaceous and early Cenozoic paleogeographic reconstructions of Biscay and Rockall areas, with inferred sediment transport axes superimposed. Orientation of continental margins is derived from land-based palaeomagnetic determinations (e.g., Smith et al., 1973).

axes of a large proportion of the samples. The same dominant shallow inclination $\chi_{\max }$ trends (northeast and north) are evident at this site, as at Hole $400 \mathrm{~A}$, but in addition there is some stringing into the northwest and southwest quadrants, and approximately 25 per cent of the samples show near-vertical $\chi_{\max }$ axes. The latter may represent the effect of regional or drilling deformation or the influence of sample shape (Kent and Lowrie, 1975). Consequently, the anisotropy data have been replotted in Figure $5 \mathrm{~b}$ after exclusion of all samples with high $\chi_{\max }$ inclinations. The resulting plot shows many similarities to that for Hole 400A (Figure 2), and in both cases the dominant feature of the $\chi_{\max }$ distribution is the northeast-southwest and north trends.

A conspicuous difference between the magnetic fabric at the two sites is the lack of a clear imbrication at Hole 402A; as with Hole $400 \mathrm{~A}$, the inferred axis of sediment transport at this site is approximately perpendicular to the contemporaneous continental margin (Figure 4a).

It seems probable that the difference in degree of imbrication is related to the differing environment of deposition. Seismic profiles indicate that a difference in relief of some 2000 meters existed between these two sites during Aptian-Albian times (Roberts, this volume), and paleontological evidence suggests that the carbonaceous mudstones at Hole 400A were probably deposited at water depths of only a few hundred meters, whereas those at Hole $402 \mathrm{~A}$ were deposited in a bathyal environment (Hailwood et al., this volume).

At Hole 402A there is lithological evidence that the sediments in the depth range 270 to 385 meters sub-bottom may have been deposited in a "delta front" environment characterized by deep channels, levees, and pools. Within this sequence, sediments from the range 335 to 385 meters sub-bottom contain mud gravels, wood fragments, and evidence for local slumps, and may have been deposited in some form of deep open channel. In contrast, sediments from the interval 270 to 335 meters sub-bottom show characteristics similar to modern "tidal flat" deposits, including laminations suggestive of variation in flow régime, slight to intense bioturbation (mostly of the interbedded marly limestones), presence of pelecypod and gastropod fragments, and well-rounded glauconite grains.

The boundary between these two facies, at approximately 335 meters sub-bottom, corresponds with an important change in the magnetic fabric characteristics (Figure 6). Below this depth the inferred "channel deposits" show rapidly varying $\chi_{\max }$ azimuths, and a higher incidence of "secondary style" fabrics, perhaps reflecting the influence of local slumps. Above this level the inferred "tidal flat" deposits show less variability in both $\chi_{\max }$ azimuth and $q$ value.

The important contribution of the magnetic fabric studies is in the recognition of a well-defined preferred alignment of grain long axes, particularly in the latter deposits, which is oriented approximately perpendicular to the contemporaneous continental margin (Figure 4a). This is consistent with the proposed model of a "delta-front" environment at Hole $402 \mathrm{~A}$ in Aptian-Albian times, with sediment being actively transported across the continental shelf, and down the continental slope towards Hole 400A.

Comparison between the $\chi_{\max }$ azimuths at these two sites (Figures 3 and 6) suggests the possible occurrence of a systematic shift of magnetic lineation trend through some 80 

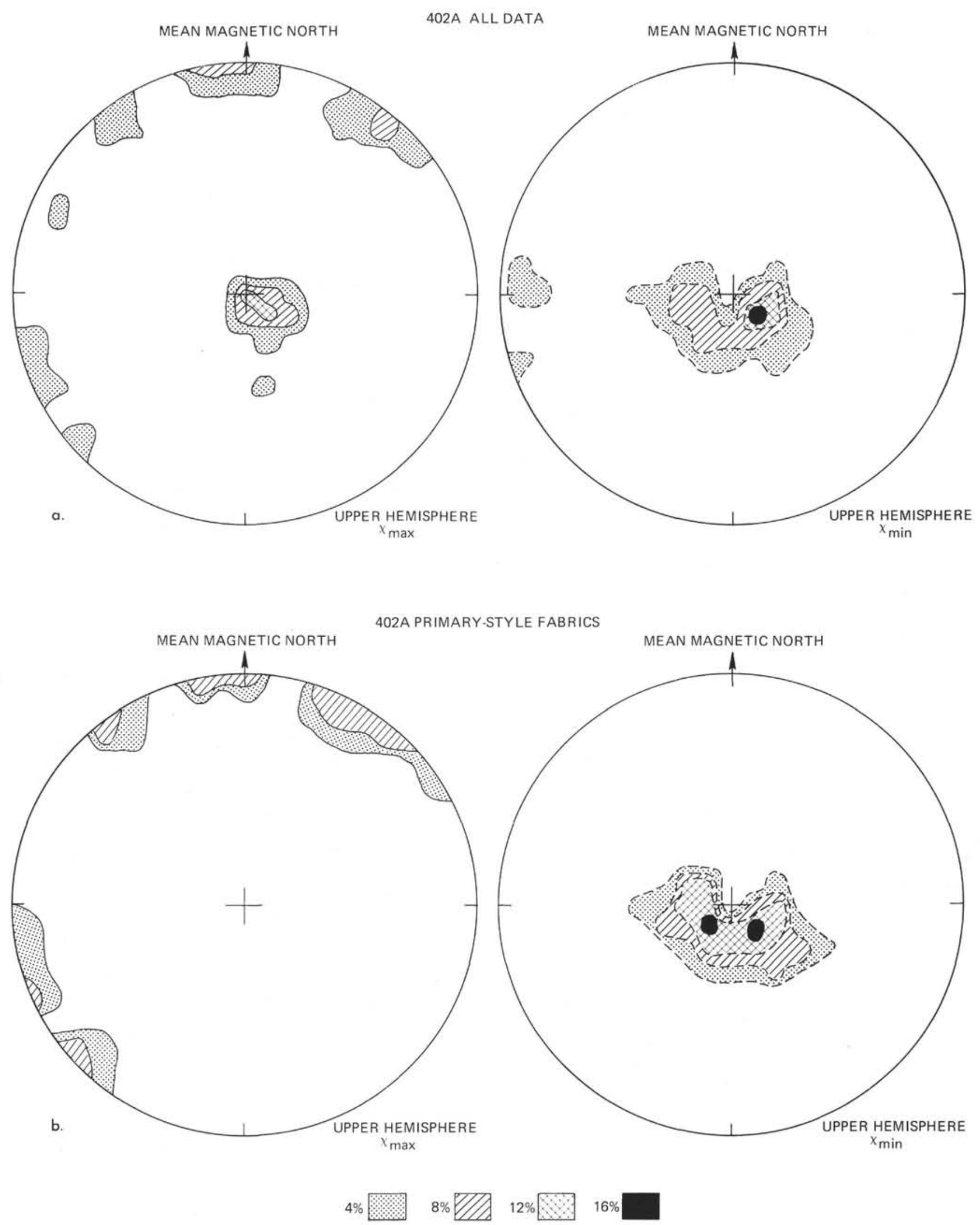

Figure 5. Contoured equal area projections of maximum and minimum principal susceptibility axes for Early Cretaceous samples from Hole $402 \mathrm{~A}$. 


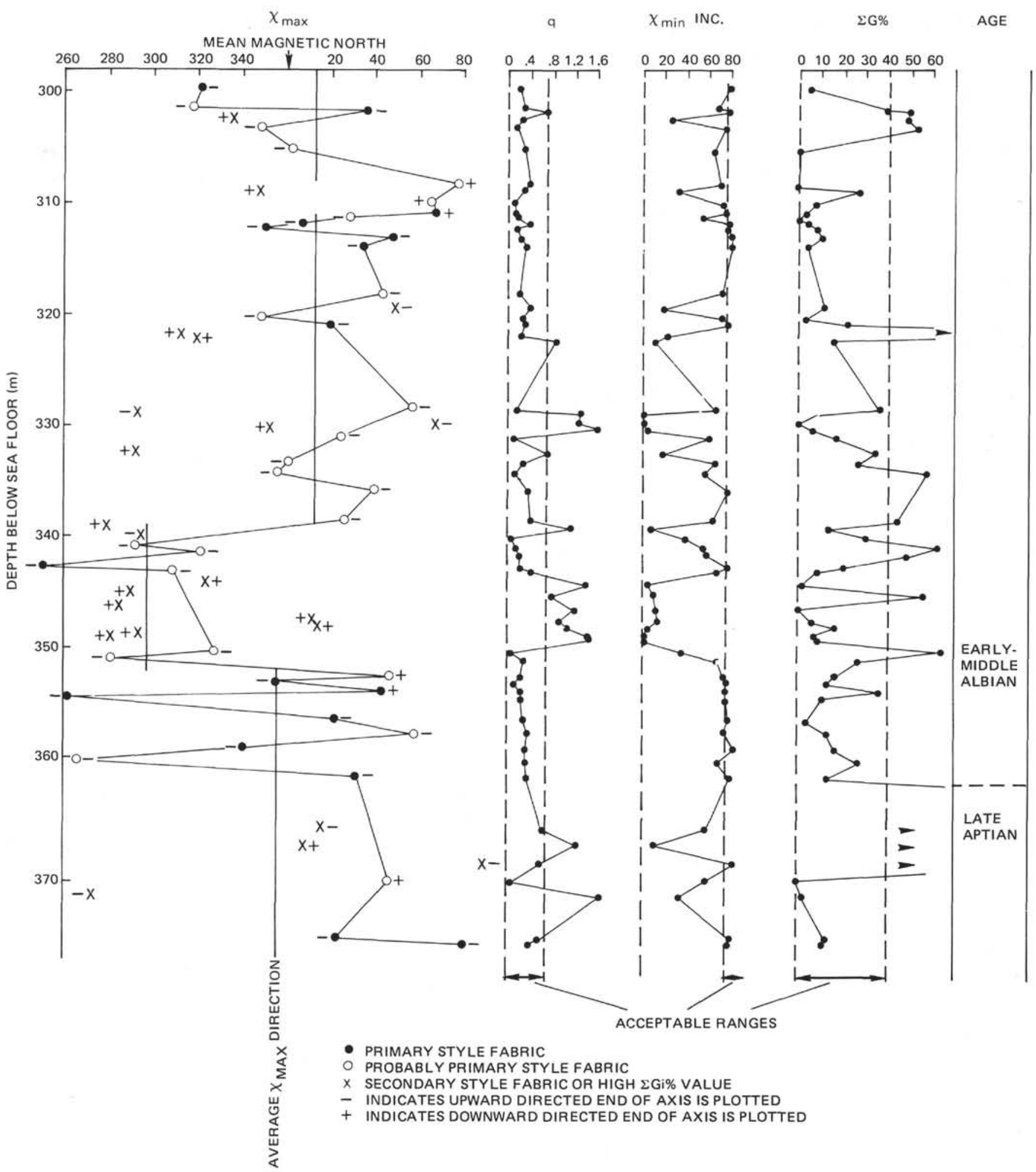

Figure 6. Downhole variation of key susceptibility parameters at Hole 402A. Symbols and notation as in Figure 3.

to 100 degrees near the base of the lower Albian at both sites. Since the recognition of this shift at Hole $400 \mathrm{~A}$ is based on only three samples, it must be regarded as highly tentative at the present time. However, if further more detailed studies bear it out, the possible occurrence of a synchronous event recorded in the preferred alignment of mineral grains at these two sites is suggested. Further speculation on the possible cause of this feature is considered premature until additional magnetic fabric studies have been completed. 


\section{Significance of Magnetic Anisotropy Determinations for Holes 400A and 402A: Origin of the Black Shales}

Laminated mudstones with high organic carbon content, frequently referred to as black shales, have been identified in DSDP cores of Jurassic, and Early and Late Cretaceous age from the Atlantic, Pacific, and Indian oceans; three contrasting models have been put forward to account for these unusual organic-rich sediments. The first (referred to here as Model 1) entails episodes of basin-wide abyssal stagnation, such as that occurring at the present time in the Black Sea (Degens and Ross, 1974) where a marked pycnocline at about 200 meters water depth separates the warm, low-salinity, well-oxygenated surface waters from the denser saline anoxic deep water masses. The resultant stable density stratification inhibits the overturning of water masses, and the oxygenation of the deeper regions. Similar episodes of basin-wide abyssal stagnation are known to have occurred in the Mediterranean Sea during the Pleistocene, and may well have occurred in the Atlantic and Indian oceans in Cretaceous times, when these oceans occupied narrow and restricted seaways, during the early stages of fragmentation of Gondwanaland. An alternative model for the origin of black shales (Model 2) involves their deposition beneath the oceanic mid-water oxygen-minimum developed beneath highly productive surface water masses along certain continental margins, particularly those associated with the upwelling systems of eastern boundary currents. This model appears to adequately account for the distribution of Late Cretaceous euxinic sediments in the South Atlantic (Thiede and van Andel, 1977) and also the fact that anoxic sediments of this age in the Pacific appear to be restricted to the flanks of seamount chains, while well-oxygenated conditions existed in deeper water (Winterer, Ewing, et al., 1973).

A third possible explanation for the origin of organic carbon-rich sediments (Model 3) is the occurrence of unusually high inputs of terrestrial organic material, particularly plant remains, derived from coastal swamps and lagoons, or transported by rivers from the continental interiors, and carried into the offshore region by submarine currents. The preservation of this material would be due more to the high rate of supply than to the existence of an anoxic environment, but the decay of such large volumes of organic material would tend to rob the bottom waters of oxygen and, perhaps, produce local euxinic conditions.

The magnetic anisotropy studies of the Aptian-Albian black shales recovered from Holes 400A and 402A have significant bearing on ascertaining which of the three alternative models is most applicable to these particular sediments. Models 1 and 2 (deposition in a stagnant basin, or beneath a local mid-water oxygen depleted zone) imply a low level of oxygen replenishment in bottom waters and, hence, sluggish bottom water movement. Model 3 (high input of terrestrial organic material) requires an extremely active downslope bottom transport mechanism.

The inferred existence of well-defined preferred orientations of magnetic mineral grains approximately perpendicular to the continental margin support the suggestion that the Aptian-Albian organic-rich sediments at shallow water Hole 402A were deposited in a "delta front" environment in which large volumes of terrestrial organic material may have been transported into the offshore region. The magnetic fabric of the deep water sediments at Hole $400 \mathrm{~A}$ is consistent with deposition on a slope, and possibly also with the periodic influx of organic-rich material from turbidity currents. Thus, although the exact depositional environment cannot yet be established from magnetic anisotropy studies, existing data from both sites are more compatible with the dynamic environment implied by Model 3, rather than the relatively static environment required for the first two models. Further evidence that the Aptian-Albian black shales at Holes 400A and 402A resulted from rapid input of terrigenous material is provided by the shipboard pyrolysis studies (Tissot et al., this volume).

\section{Paleocene-Eocene Tuffaceous Mudstones From Rockall}

Magnetic fabric determinations have been completed on a total of 76 samples from the early Paleogene sediments of deltaic aspect recovered at Site 403, near the rifted westerly margin of the Rockall Plateau. Of these, 56 per cent show a definite primary style magnetic fabric; 28 per cent show $\Sigma G_{i} \%$ values close to 40 per cent or $q$ and $\chi_{\min }$ inclination values that are just outside the "primary style" limits, and have been classified as "probably primary style." The remaining 16 per cent have been rejected, either because they show clear "deformational style" fabrics, or $\Sigma G_{i}$ per cent values $>40$ per cent, that could reflect significant instrumental errors.

A contoured equal area projection of the maximum and minimum susceptibility axes for the samples from this site showing "primary" and "probably primary" style fabrics is shown in Figure 7. Although the orientation of $\chi_{\max }$ axes extends over a wide range of azimuths, the highest concentrations occur within or close to the southeast quadrant. This effect is also apparent in the downhole plot (Figure 8 ), from which it is clear that no systematic change with depth in $\chi_{\max }$ azimuth can be identified.

The overall average $\chi_{\max }$ azimuth is plotted on a paleomagnetic reconstruction of the northeast Atlantic region for early Paleogene times in Figure $4 \mathrm{~b}$. The inferred axis of bottom transport is approximately perpendicular to the incipient continental margin between Greenland and Rockall. It is noteworthy that the $\chi_{\max }$ axes are directed upwards in a southeast direction, i.e., the direction of upward imbrication is consistently away from the Greenland margin. The overall mean $q$ value for these sediments is $0.29 \pm 0.03$, which value lies within the range normally encountered in laboratory experiments for grain-by-grain deposition from running water. There appear to be no geological reasons for suspecting that these shallow water sediments may have been deposited from concentrated suspensions such as turbidity currents. Thus, assuming grain-by-grain deposition from bottom currents, the results from Site 403 are consistent with transport of the early Paleogene sediments from the northwest (Greenland) rather than from the southeast (Rockall). At first sight this seems somewhat surprising, in view of the present location of the site on a margin which slopes to the northwest. However, paleomagnetic measurements indicate that the entire 


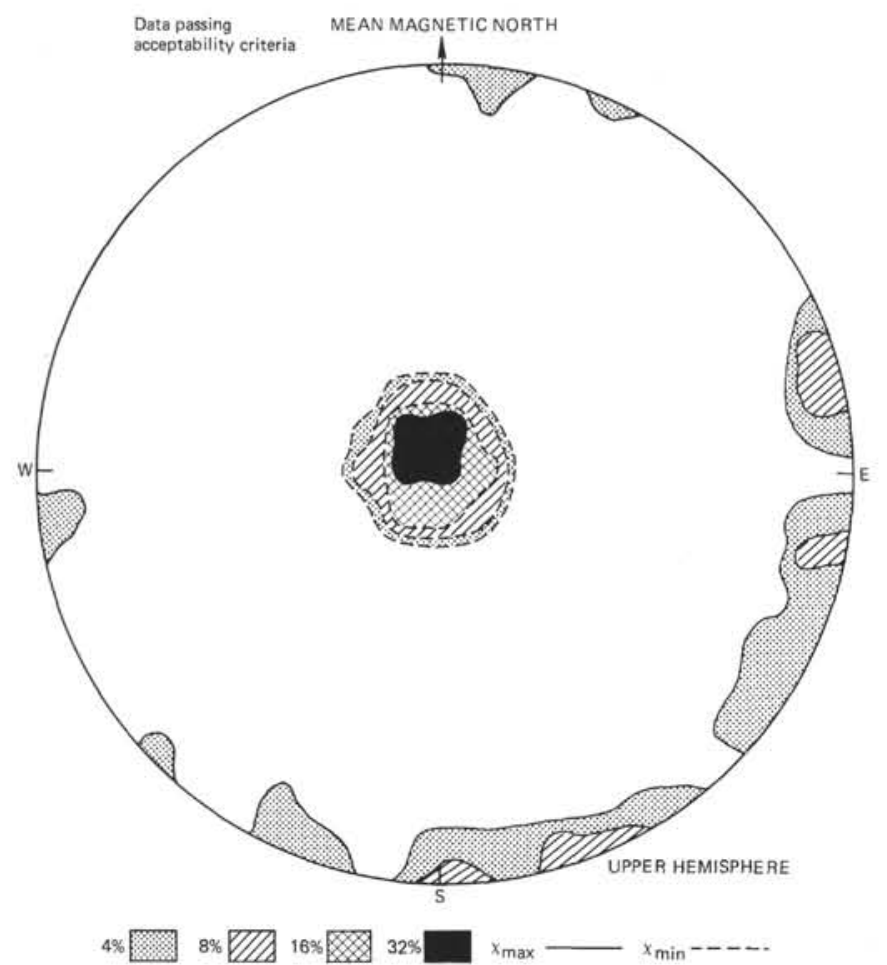

Figure 7. Contoured equal area projection of maximum and minimum principal susceptibility axes for early Paleogene samples from Site 403.

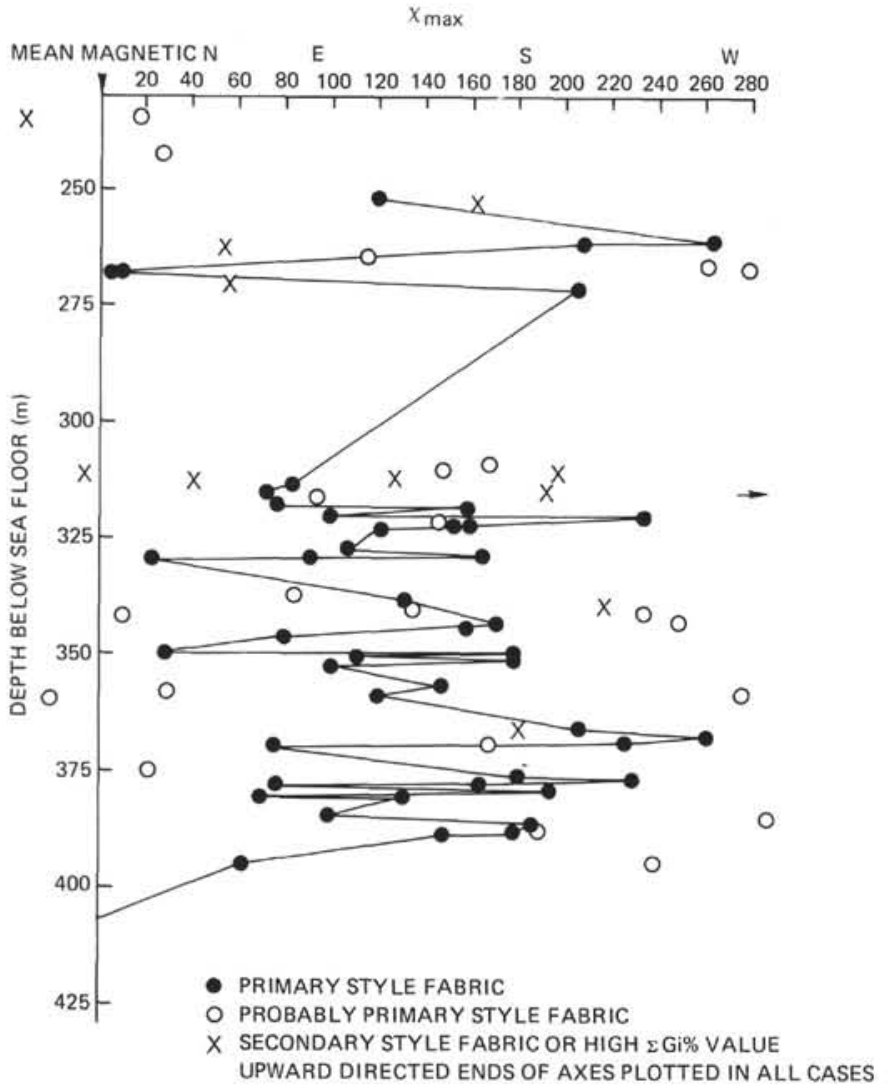

200-meter section of early Paleogene sediments at Site 403 is reversely magnetized (Hailwood, this volume). A comparison with the magneto-biostratigraphic record for nearby Sites 404 and 405 indicates that these sediments acquired their magnetization during the long reverse polarity interval that preceded anomaly 24 , the oldest marine magnetic anomaly in the Northeast Atlantic. Consequently these sediments were probably deposited during the very early stages of rifting of Rockall from East Greenland, possibly before Site 403 had been detached from the East Greenland margin. The inferred early Paleogene direction of sediment transport towards the southeast at Site 403 is consistent with this proposed tectonic history.

\section{CONCLUSIONS}

Detailed magnetic anisotropy determinations from the Lower Cretaceous black shales cored at Holes 400A and $402 \mathrm{~A}$ in the Bay of Biscay reveal a well-developed magnetic lineation. It is proposed that this lineation was produced by a strong and persistent bottom transport mechanism, oriented perpendicular to the contemporaneous continental margin. The existence of such an active transport mechanism makes it unlikely that the high organic carbon content of these sediments results from their deposition in a stagnant basin, and supports the alternative view that their organic-rich nature results from an unusually high influx of terrigenous plant material, perhaps derived from coastal swamps and lagoons.

q

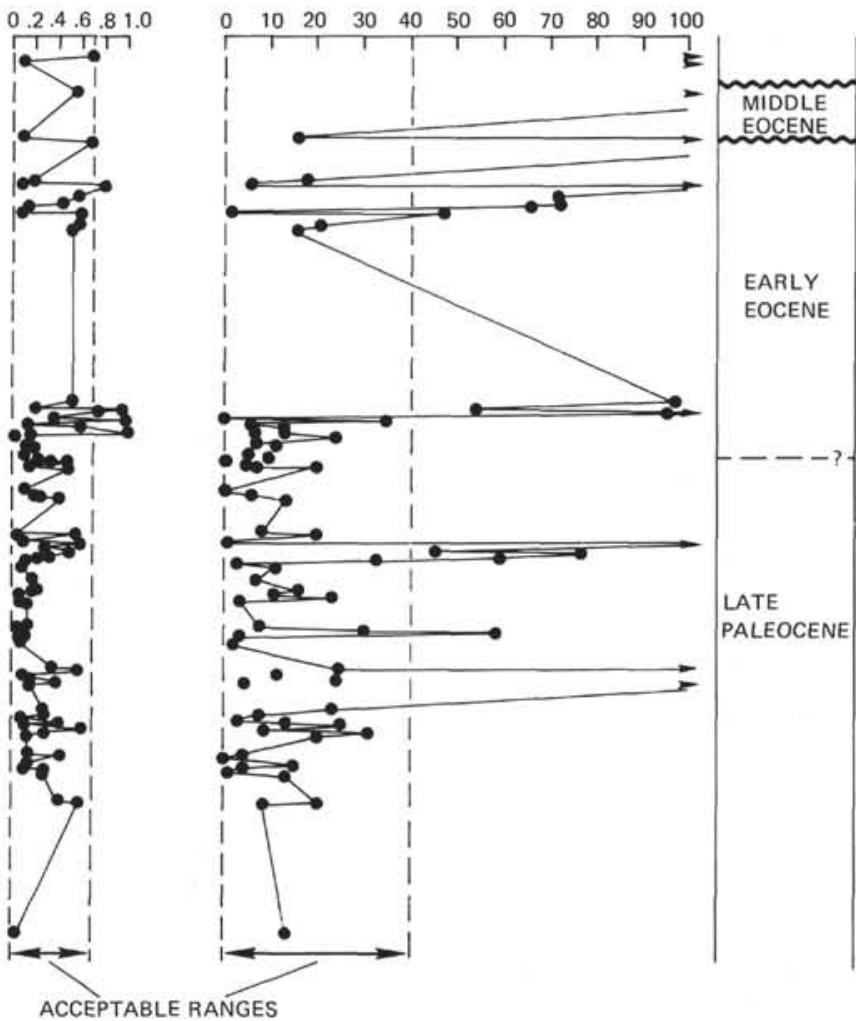

Figure 8. Downhole variation of key susceptibility parameters at Site 403. Symbols and notation as in Figure 3. 
The magnetic anisotropy of the thick sequence of glauconitic mudstones and volcaniclastic siltstones cored at Site 403, near the rifted westerly margin of the Rockall Plateau, also reveals a strong preferred grain alignment approximately perpendicular to the present continental margin. However the imbrication of the $\chi^{\max }$ axes is consistent with transport from the northwest, rather than the southeast, and supports the view that these sediments were laid down within a "deltaic" complex which drained the southern part of East Greenland in late Paleocene and early Eocene times. Final separation of the Rockall Plateau, including part of this deltaic complex, from East Greenland occurred in the early Eocene, and this tectonic event is probably represented by the hiatus between the early and middle Eocene sediments at Site 403 (Figure 8).

\section{ACKNOWLEDGMENTS}

We are very grateful to Pat Copland for her invaluable assistance with anisotropy measurements of the Site 403 samples. We would also like to thank Tony Rees and Norman Hamilton for their helpful reviews of the manuscript. Financial support has been provided by the Natural Environment Research Council.

\section{REFERENCES}

Degens, E.T. and Ross, D.A. (Eds.), 1973. The Black Sea: Its geology, chemistry and biology: Am. Assoc. Petrol. Geol. Mem., v. 20 , p. $1-663$.

Hamilton, N., 1967. The effect of magnetic and hydrodynamic control on the susceptibility anisotropy of redeposited silts, $J$. Geol., v. 75 , p. $738-743$.
Hamilton, N. and Rees, A.I., 1970. The use of magnetic fabric in paleocurrent estimation. In Runcorn, S.K. (Ed.), Palaeogeophysics: New York (Academic Press), p. 445-464.

Kent, D.V. and Lowrie, W., 1975. On the magnetic susceptibility anisotropy of deep-sea sediment, Earth Planet. Sci. Lett., v. 28 , p. $1-12$.

King, R.F. and Rees, A.I., 1962. The measurement of the anisotropy of magnetic susceptibility of rocks by the torque method, J. Geophys. Res., v. 67, p. 1565-1572.

Rees, A.I., 1966. The effect of depositional slopes on the anisotropy of magnetic susceptibility of laboratory deposited sands, J. Geol., v. 74, p. 856-867.

, 1968. The production of preferred orientation in a concentrated dispersion of elongated and flattened grains, $J$. Geol., v. 76, p. 457-465.

Rees, A.I. and Frederick, D., 1974. The magnetic fabric of samples from the Deep Sea Drilling Project, Legs I to VI, $J$. Sediment. Petrol., v. 44, p. 655-662.

Rees, A.I. and Woodall, W.A., 1975. The magnetic fabric of some laboratory-deposited sediments, Earth Planet. Sci. Lett., v. 25 , p. $121-130$.

Smith, A.G., Briden, J.C., and Drewry, G.E., 1973. Phanerozoic World Maps. In Organisms and Continents Through Time: Systematics Association Publication 9, Special Papers in Palaeontology No. 12. London (Palaeontological Association), p. $1-42$.

Thiede, J. and van Andel, T.H., 1977. The paleoenvironment of anaerobic sediments in the Late Mesozoic South Atlantic Ocean, Earth Planet. Sci. Lett., v. 33, p. 301-309.

Winterer, E.L., Ewing, J.I., et al., 1973. Initial Reports of the Deep Sea Drilling Project, v. 17: Washington (U.S. Government Printing Office). 